\title{
La Pedra da Póvoa (Trás-os-Montes, Portugal). Una pieza escultórica de la Edad del Hierro
}

\author{
The Pedra da Póvoa (Trás-os-Montes, Portugal). A carved monolith of the Iron Age
}

\author{
João Fonte (*) \\ Manuel Santos Estévez (**) \\ Lara Bacelar Alves (***) \\ Raquel López Noia (****)
}

\section{RESUMEN}

Se da a conocer la Pedra da Póvoa (Póvoa, Ribeira de Pena), un monolito inédito, grabado con motivos abstractos y un zoomorfo. Consideramos posible fecharlo en la Edad del Hierro del Noroeste Peninsular. Se presentan las condiciones del hallazgo, emplazamiento y descripción tecno-morfológica de los grabados y se plantean algunas consideraciones en torno a su contextualización crono-estilística.

\begin{abstract}
This paper offers a preliminary study of Pedra da Póvoa, a carved monolith displaying curvilinear motifs and one deer, possibly dated to the Iron Age, which was recently discovered in Northern Portugal. It provides an account of the find conditions, spatial environment, a description of the engravings and a preliminary discussion of its chronological and stylistic contexts.
\end{abstract}

Palabras clave: Noroeste peninsular; Edad del Hierro; Monolito insculturado.

(*) LaPa. Laboratorio de Patrimonio, CSIC. Instituto de Estudos Galegos Padre Sarmiento. San Roque 2. 15704 Santiago de Compostela. Correo electrónico: joao.fonte@iegps.csic.es

(**) LaPa. Laboratorio de Patrimonio, CSIC. Instituto de Estudos Galegos Padre Sarmiento. San Roque 2. 15704 Santiago de Compostela. Correo electrónico: manuel.santos@cchs.csic.es

(***) Centro de Estudos Arqueológicos das Universidades de Coimbra e Porto - Campo Arqueológico de Mértola (CEAUCP-CAM). Palácio de Sub-Ripas. 3000-395 Coimbra, Portugal. Correo electrónico: larabacelar@gmail.com

(****) LaPa. Laboratorio de Patrimonio, CSIC. Instituto de Estudos Galegos Padre Sarmiento. San Roque 2. 15704 Santiago de Compostela.

Correo electrónico: raquel.lopez-noia@iegps.csic.es Recibido: 17-III-2009; aceptado: 16-IX-2009.
Key words: North-west Iberia; Iron Age; Carved monolith.

\section{CIRCUNSTANCIAS DEL HALLAZGO}

La Pedra da Póvoa fue documentada en el ámbito del proceso de catalogación de sitios arqueológicos que la extensión de Macedo de Cavaleiros del extinto Instituto Português de Arqueologia (IPA) realizó, en 2007, en la aldea de Póvoa, freguesia de Salvador, ayuntamiento de Ribeira de Pena, distrito de Vila Real, provincia de Trás-os-Montes (Norte de Portugal). La información sobre su descubrimiento es dada por Emanuel Ribeiro, técnico de patrimonio del Ayuntamiento de Ribeira de Pena. El monolito fue recogido por un agricultor de la aldea de Póvoa, en un terreno de cultivo situado en la margen izquierda del río Louredo, propiedad de Maria José Martins de Andrade Borges Carvalhinho, en cuya residencia se encuentra la referida piedra y a quién queremos agradecer toda la disponibilidad y facilidades concedidas en el estudio de la Pedra da Póvoa.

Conocimos la existencia de la Pedra da Póvoa en la base de datos patrimonial del ex-IPA y actual IGESPAR, I.P. -Endovélico- donde aparece con la referencia CNS 28188 y a través de un contacto previo con el arqueólogo António Luís Pereira, técnico de la extensión de Macedo de Cavaleiros del IGESPAR, I.P., que gentilmente nos cedió fotografías de la pieza, además de algunas informaciones adicionales. Uno de nosotros (JF) procedió a una primera evaluación del ha- 
llazgo in loco $\mathrm{y}$, para su divulgación, dado su innegable interés científico, y el hecho de no encontrarse en las mejores condiciones para su conservación, se planteó un proyecto de investigación denominado: "Estudo Monográfico e Levantamento da Pedra da Póvoa, Ribeira de Pena". Obtenida la necesaria autorización para la realización de los trabajos arqueológicos, emitida por el IGESPAR, IP, se procedió, en abril de 2008, a un completo registro gráfico y fotográfico de la Pedra da Póvoa, aprovechando la ocasión para indagar sobre las circunstancias en que tuvo lugar el descubrimiento.

\section{LOCALIZACIÓN GEOGRÁFICA Y CONTEXTO ARQUEOLÓGICO}

Como ya se ha mencionado, la Pedra da Póvoa apareció de forma casual durante remociones de tierra con arado en las áreas de inundación del río Louredo. El uso y dedicación de estas áreas es la obtención de pastos durante todo el año, debido a su abundante y permanente humedad. Dadas las características del hallazgo podemos decir que éste probablemente no se encuentra in situ, aunque no habría que descartar que su posición original no se hallase lejos del lugar de hallazgo.

La aldea de Póvoa y su entorno se caracterizan por una accidentada y antigua topografía debido a numerosas sierras y mesetas graníticas entre las que se intercala una densa y encajada red hidrográfica dominada por la cuenca del río Duero.

La zona que nos ocupa se encuentra al norte del distrito de Vila Real, en los límites occidentales de la provincia de Trás-os-Montes, muy próxima a la zona de transición a las tierras de Minho, de ahí que presente características de ambas áreas geográficas. Por un lado, la topografía se presenta como una sucesión de pequeñas sierras de cimas redondeadas, estribaciones de las sierras próximas como la de Larouco y Alvão. Entre éstas aparecen los valles y tierras bajas por las que discurre el río Tâmega que articula la zona y que la asemeja a las tierras litorales del Miño, caracterizadas por la presencia de valles fluviales dominados por la agricultura (Fig. 1).

El lugar del hallazgo se encuentra en el margen izquierdo del río Louredo, afluente del Tâmega, a su paso por las proximidades de la aldea de Póvoa. Es una zona llana, de tierras bajas e inundables. El río presenta un vado natural que coin- cide con otro paso habitual, un collado que facilitó el tránsito especialmente en la Prehistoria, entre las tierras altas de montaña y las zonas de valle. Este collado está rodeado por cimas que en algunos casos superan los $1000 \mathrm{~m}$ de altura como

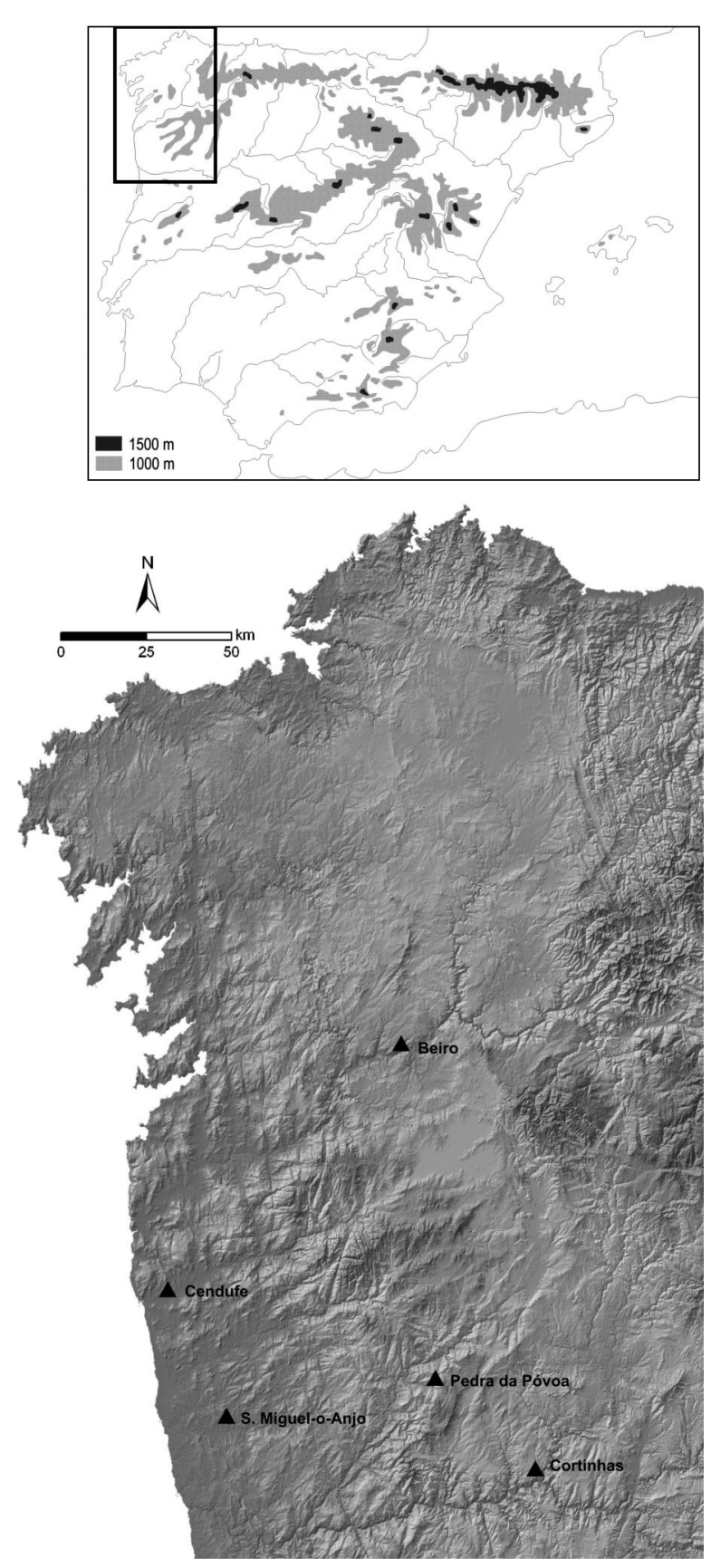

Fig. 1. Localización de la Pedra da Póvoa y distribución de las denominadas "piedras onfálicas" en el Noroeste de la Península Ibérica. 
el Alto de Chã, a cuyos pies y al noreste se encuentra el lugar del hallazgo; al sudoeste el Alto da Armada, al noroeste el Alto da Subidade, al norte el Alto do Facho y al noreste la cima conocida como Choupica con $1025 \mathrm{~m}$. La consideración de esta zona como de tránsito y/o frontera, favorecida por las condiciones naturales del relieve, se refleja en la presencia del topónimo Portela de Santa Eulália, en las inmediaciones de la aldea de Póvoa: zona de paso y encrucijada de caminos que además es el límite natural de dos regiones administrativas del Norte de Portugal, Trás-osMontes (hacia el norte) y Minho (hacia el sur). Podrá también ser significativo el hecho de que el lugar en el que apareció la piedra se encuentra próximo a un puente histórico, posiblemente de origen medieval, y que en tiempos anteriores pudo haber sido una zona de vadeo (Lám. I).

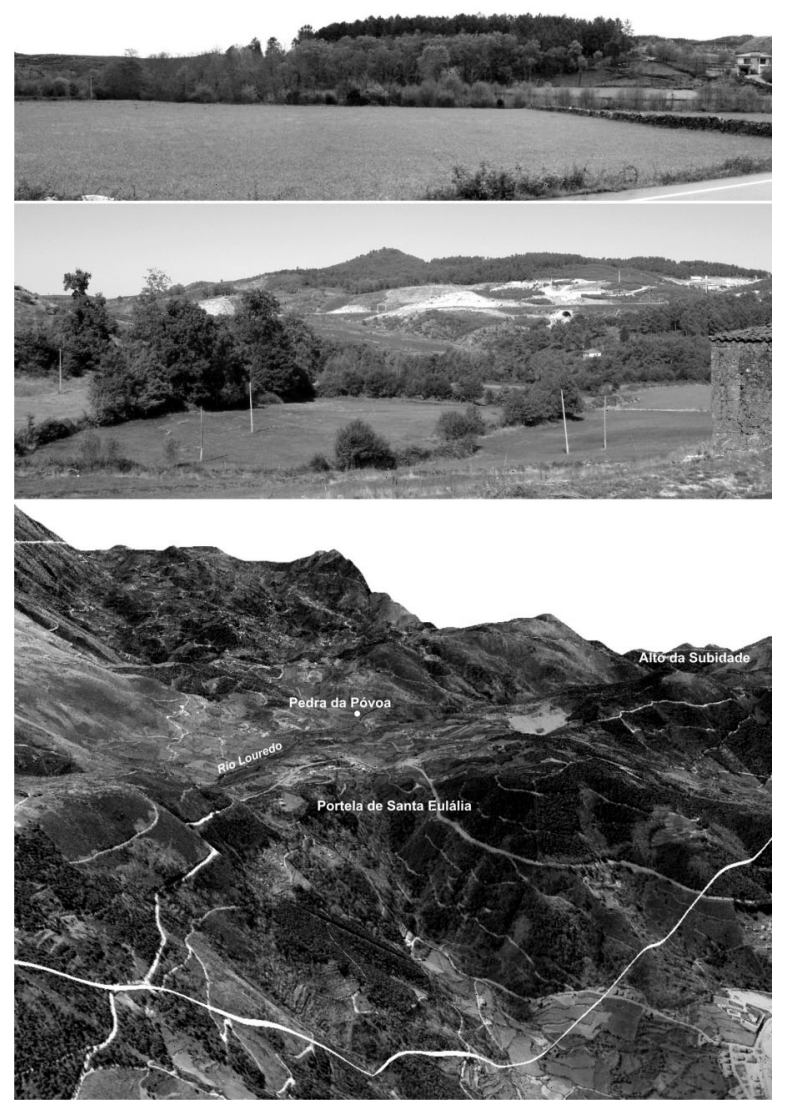

Lám. I. Diferentes vistas del lugar de hallazgo de Pedra da Póvoa. La imagen inferior se corresponde con un modelo digital de elevaciones (MDE) con ortofotos de la zona sobrepuestos.
En el Alto da Subidade se localiza un poblado fortificado con ocupación de la Edad del Hierro, que controla visualmente todo el valle y que, aunque no está clara su contemporaneidad con la Pedra da Póvoa, es muy posible la pertenencia de ambas entidades arqueológicas al mismo período. Como elementos arqueológicos más relevantes asociados a este sitio destaca un brazalete y seis cuentas en oro introducidas en un hilo metálico pertenecientes a un collar articulado (Vasconcelos 1917; Menezes 1929; Carvalho 1981). Señalemos también el hallazgo de un puñal de lengüeta y de una punta "tipo Palmela" que podría testificar una cronología más antigua para la ocupación de este sitio (Comendador Rey 1999: 59). Muy cerca se localiza el Monte da Senhora da Graça (Mondim de Basto), donde se sitúan los grabados rupestres de Campelo y el conjunto descubierto dentro del perímetro del Castro de Castroeiro (Dinis 2001), ambos pertenecientes a la tradición del Arte Rupestre Atlántico.

\section{DESCRIPCIÓN \\ TECNO-MORFOLÓGICA DE LOS GRABADOS DE LA PEDRA DA PÓVOA}

La Pedra da Póvoa es un bloque granítico exento de forma aproximadamente paralelipédica con $0,57 \mathrm{~m}$ de altura y $0,20 \mathrm{~m}$ de ancho, aunque la base es ligeramente más ancha que la parte superior, ofreciendo de esta forma un aspecto vagamente troncopiramidal. Presenta las cuatro caras perfectamente definidas, cada una con la superficie regularizada mediante una cuidada abrasión (en el calco se indican estas áreas alisadas en gris claro). La ausencia de preparación en la base del bloque, así como la posición de las figuras y el perfil ligeramente troncopiramidal, parece indicar que la pieza fue concebida para ser colocada en posición vertical.

La cara A tiene un perfil subtrapezoidal y una superficie perfectamente regularizada por alisamiento (Fig. 2). Presenta dos motivos tangentes, formados por surcos curvilíneos. En la zona superior aparece una figura de morfología genéricamente circular, constituida por un pequeño círculo interno, de cuya parte superior parte una línea que se diluye en la extremidad superior del panel. De ésta arranca un arco que circunscribe el primer anillo aunque su extremo no coincida con el surco de la línea recta medial. Lo mismo ocurre 


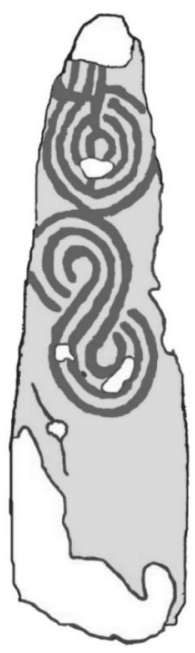

A

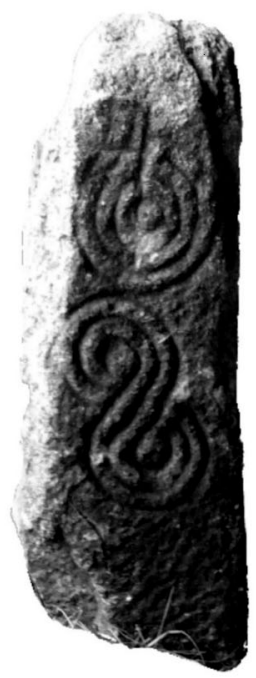

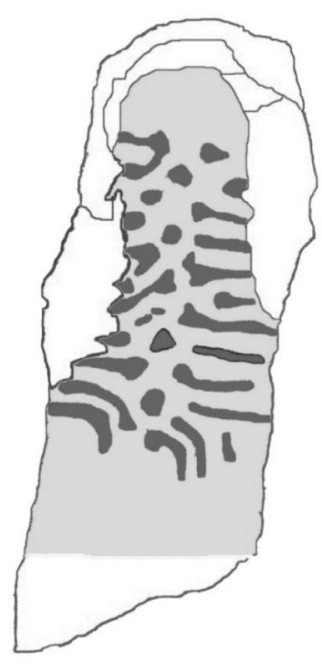

B

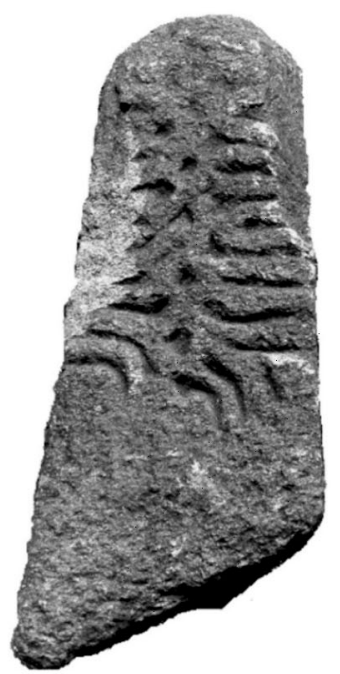

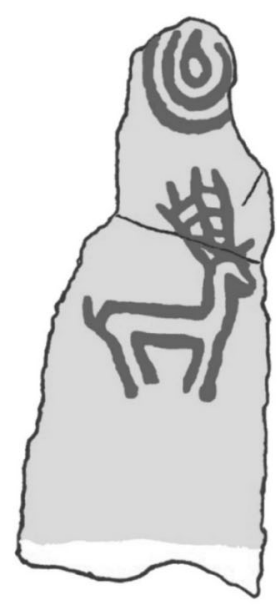

C

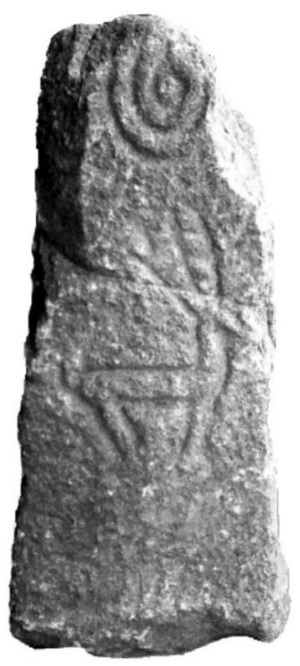

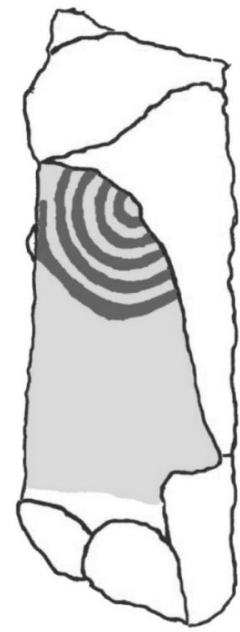

D

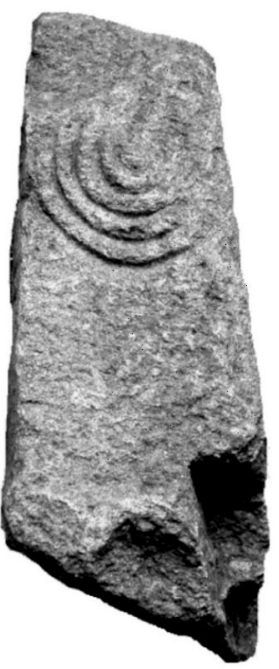

$25 \mathrm{~cm}$

Fig. 2. Calcos y fotografías de las cuatro caras de la Pedra da Póvoa. En gris oscuro están representados los surcos, en gris claro la superficie alisada del soporte.

con el tercer arco, que se desarrolla desde el lado izquierdo, describiendo una suave curva, en dirección a la parte alta del panel. El segundo y tercer arco, que envuelven el círculo central, se unen por un pequeño segmento lineal. El surco circular externo parte del lado derecho de la línea medial y describe el mismo recorrido en dirección a la fractura superior. Es de destacar que el surco medial, originalmente con un perfil en $U$ abierta, parece haber sido regrabado con instrumento aguza- do y que las dos líneas externas que rematan en la parte alta del panel les fue superpuesta una línea toscamente grabada. En suma, esta figura, parcialmente afectada en la zona central por una fractura reciente, no es una clásica combinación de círculos concéntricos propia del Arte Rupestre Atlántico aunque sí debemos considerarla como una variante original constituida por círculo central con apéndice radial y tres arcos de círculos concéntricos. 


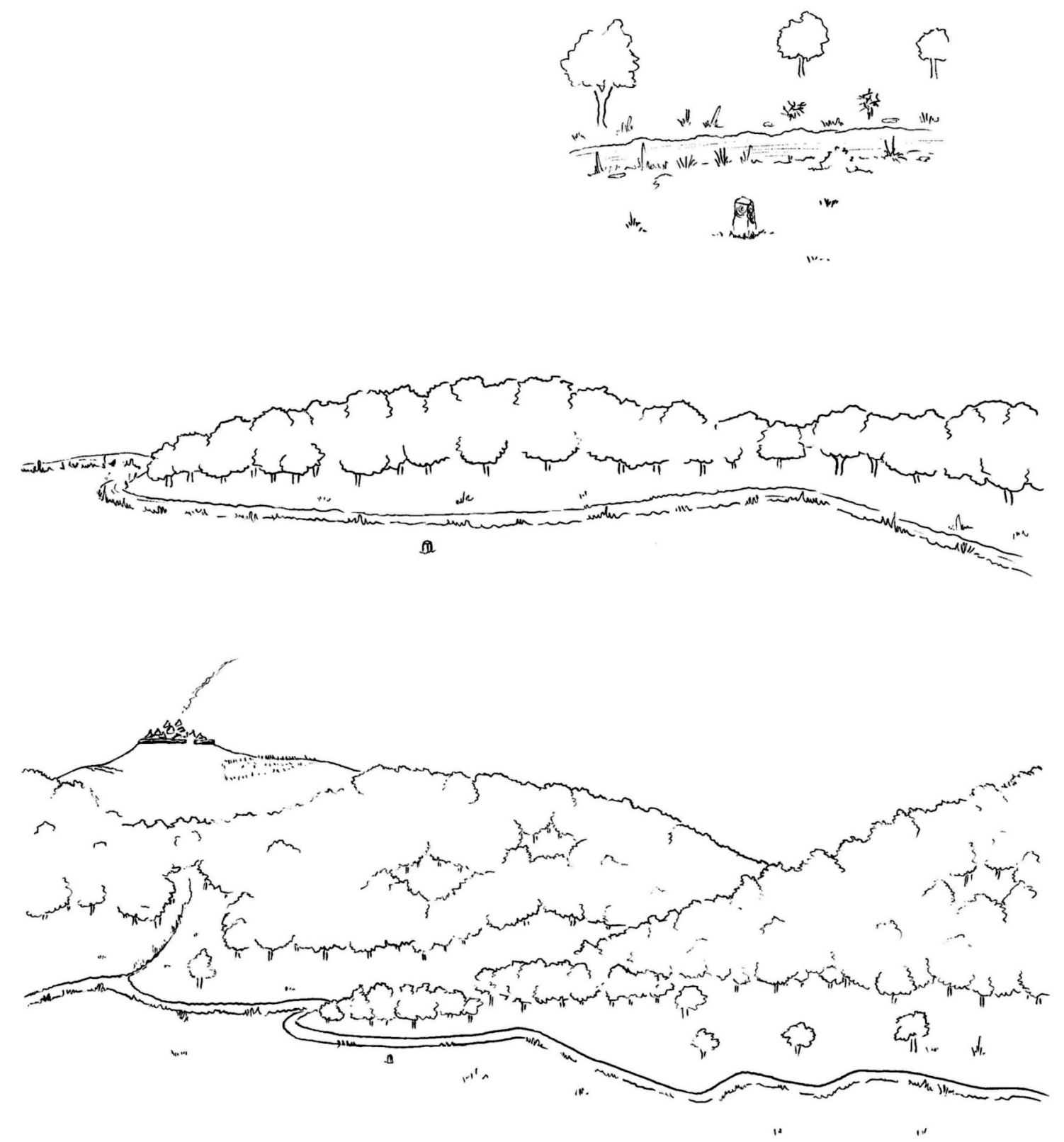

Fig. 3. Recreación del paisaje y de la probable ubicación original de la Pedra da Póvoa. En el horizonte se divisaría el castro de Alto da Subidade. Dibujo de Anxo Rodríguez Paz.

El segundo motivo de esta cara A se podría relacionar con los motivos decorativos del tipo "SS" recurrentes en la gramática figurativa "castreña" y que en este caso está compuesto por tres surcos en S paralelos. La técnica de grabado aplicada en esta figura fue, como en la anterior, un fino piqueteado, por lo que presenta un surco con perfil en U estrecha con un contorno y tratamien- to interior más regular. Teniendo en cuenta la simetría casi perfecta que presenta, es posible que la figura hubiese sido previamente delineada sobre el soporte antes de ser grabada. Las decoraciones del tipo "SS" suelen aparecer decorando elementos arquitectónicos y generalmente articulados en encadenamientos verticales u horizontales, como en un elemento decorativo procedente 


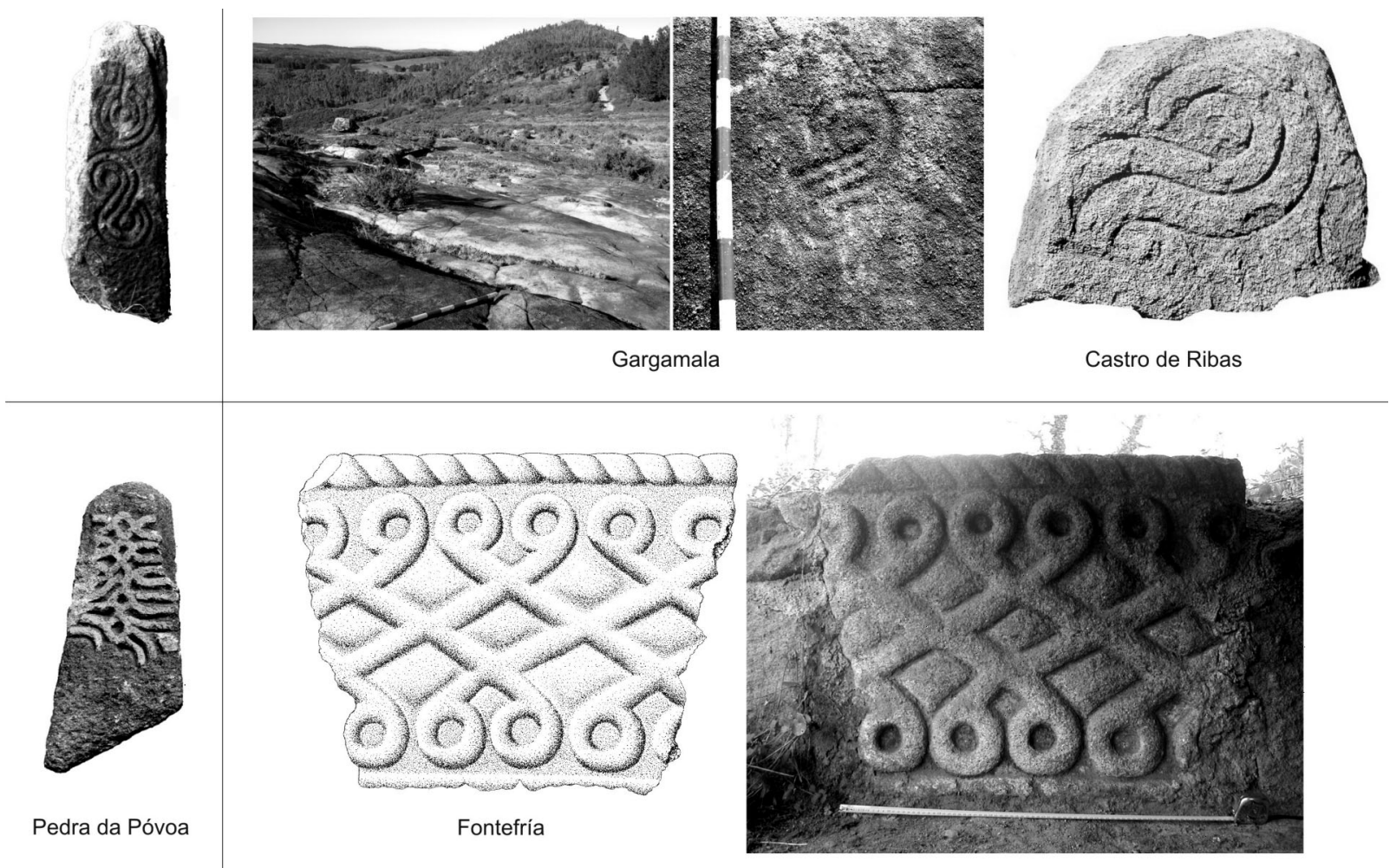

Lám. II. Arriba, cara A de la Pedra da Póvoa y grabados rupestres con decoración similar: petroglifo de Gargamala (Mondariz-Pontevedra) y Castro de Ribas (Valpaços-Vila Real). Abajo, fotografía retocada de la cara B de la Pedra da Póvoa para resaltar la figura cuyo diseño recuerda a la escultura de Fontefría (Amoeiro-Ourense).

del Castro de Ribas (Valpaços, Portugal) (Freitas 2001), pero, en cambio, para el caso de los monolitos decorados, parece ganar valor de símbolo o signo unitario, lo cual también es observable al menos en un petroglifo al aire libre, como el grabado del conjunto de Gargamala (Mondariz-Galicia) (Lám. II).

La cara B, situada a la derecha de la anterior (Fig. 2), presenta una serie de líneas y puntos. Estos últimos tienden a alinearse, en el centro del panel, siguiendo su eje longitudinal. Genéricamente, las líneas, horizontales y paralelas parten del contorno externo del panel y se disponen a ambos lados de la línea de cazoletas, uniéndose a éstas en dos casos. En una primera observación de la decoración de esta cara concluimos que debía de tratarse de un conjunto inconexo de líneas y puntos, pero tras un análisis más detenido pudimos advertir que en realidad estábamos viendo la imagen en negativo, este efecto también es frecuente en observaciones del Arte Rupestre Atlántico (Santos 2008a), tanto en los referidos grabados rupestres como en el caso de esta cara de
Pedra da Póvoa, la imagen que el artista pretendía representar es la comprendida entre los surcos, de este modo la figura plasmada puede ser un entrelazado de 10 "cuerdas" que forman cinco nudos en la parte central, configurando un eje de simetría (Lám. II) (1). Este diseño recuerda a otros vinculables a la escultura galaica como el de Fontefría en Amoeiro (Ourense-Galicia) (Arizaga et al. 2006: 109). Esta forma de ver la figura es perfectamente aplicable al resto de las caras de la piedra. De hecho, si consideramos que la figura es la comprendida entre los surcos, podemos explicar la presencia del asta central de la cornamenta del ciervo, cuya finalidad es delimitar las puntas que convergen en el centro de la cornamenta. Esta técnica empleada para la ejecución de los decorados aproxima más la pieza al Arte Rupestre Atlántico que a la propia escultura galaica.

(1) Por razones de coherencia técnica hemos preferido mantener la figura de la cara $\mathrm{B}$ en negativo siguiendo los convencionalismos tradicionales de los calcos para el arte rupestre. 
La cara $\mathrm{C}$, situada a la derecha de la anterior y en la cara opuesta a la cara A, presenta, en la parte superior, una figura difícil de reconstituir por encontrarse truncada por la fractura del límite superior del panel. Son apenas visibles dos arcos ovalados concéntricos que circundan una pequeña figura oval cerrada. En el caso de que se tratase de una variante de motivos en "SS", similar al que está presente en una de las caras de $\mathrm{S}$. Miguel-o-Anjo (Fig. 4), tendríamos que plantear la posibilidad de que la altura de la pieza fuera bastante superior a la actual, pero, teniendo en cuenta la forma de la pieza, con tendencia a estrecharse hacia la parte superior, nos inclinamos por considerar que esta figura estaría completa en su casi totalidad.
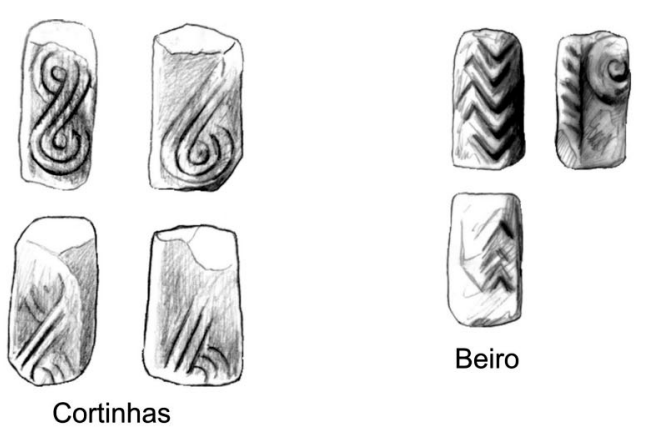

Beiro

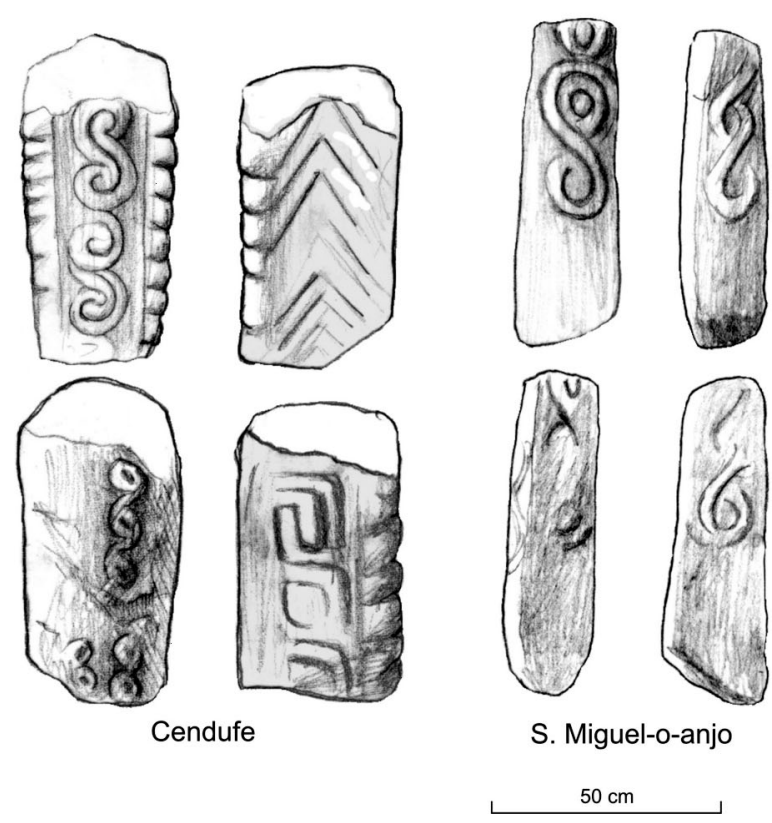

Fig. 4. Las denominadas "piedras onfálicas" del Noroeste de la Península Ibérica (fuente: González Ruibal 2006-07: 549; Fig. 4.180).
Inmediatamente debajo, y en el centro del panel, surge una magnífica representación de un venado orientado hacia la derecha, ostentando una cornamenta que aparenta estar formada por tres astas rectas ramificadas. La figura fue, como las otras, abierta por piqueteado, produciendo un surco que mantiene profundidades que oscilan entre $\operatorname{los} 0,3$ y los $0,5 \mathrm{~cm}$. Esto se debe al buen estado de conservación de la pieza que, por encontrarse enterrada, no fue tan afectada por la erosión, como sucede en la mayoría de los grabados rupestres en superficies al aire libre, esto unido al hecho de que los grabados de todas las caras fueron realizados con instrumento metálico, posiblemente hierro, permitió realizar surcos más estrechos y profundos, más fáciles de observar. La morfología y recursos estilísticos utilizados en esta representación parecen obedecer, de forma genérica, a los convencionalismos patentes en los más característicos petroglifos de cérvidos asociados al arte rupestre de tradición Atlántica del Noroeste Peninsular: un surco único describe el contorno externo del cuerpo del animal perfilando una de las patas traseras y una delantera, siendo las otras dos y la línea ventral delineadas a través de un segundo surco independiente. Hay que señalar la presencia de las características astas desproporcionadas en relación al tamaño del animal y del recurso a la figuración de la cornamenta en perspectiva torcida, con las ramificaciones o puntas orientadas hacia el interior, elementos comunes a aquellas representaciones de ciervos del territorio gallego y Alto Minho portugués.

Los elementos más originales de este motivo de la cara $\mathrm{C}$ se centran precisamente en la zona de la cabeza y cornamenta (Fig. 2). Destaca, desde luego, la presencia de un contra-estoque en perfil, acompañando la línea de la cabeza, "guarda avanzada" de una poderosa armazón con dos astas laterales, cada una de ellas provista de tres ramificaciones paralelas y simétricas que se unen a una asta central. La punta superior de la cuerna del lado izquierdo ostenta otra dispuesta en vertical. Es posible que aquella asta central pueda representar una ramificación que parta del límite inferior del asta del lado derecho (la verdad es que una fisura del soporte afecta al arranque del asta central, dificultando la lectura de esta zona) pero esto no contradice lo inédito de esta representación que pudiera encerrar un cariz mitológico u obedecer a razones técnicas. De hecho, si consideramos la imagen en negativo y que la figura es 
la comprendida entre los surcos, podemos explicar la presencia del asta central de la cornamenta del ciervo, cuya finalidad es delimitar las puntas que convergen en el centro de la cornamenta según la indicada convención propia del Arte $\mathrm{Ru}-$ pestre Atlántico.

Otro aspecto interesante se relaciona con la estilización del contorno de la cabeza y con el cuidado notorio en la definición de su parte delantera. De hecho, se observa un desbastado más amplio en esta zona que produjo un surco demasiado ancho, pero cuyo límite interno permitió modelar un cuello estrecho con una curvatura acentuada, la cual se traduce en un afilado hocico. De esta forma, la cabeza del ciervo destaca más visualmente. Su contorno recuerda también, en cierta forma, a la morfología de algunas cabezas de ciervo de la Edad del Hierro en el Vale do Côa y en el Vale da Casa, en el Douro Portugués (2) (Baptista 1999).

Estamos, entonces, ante una imagen (¿mitográfica?) de un ciervo, figurado en una etapa determinada de su ciclo anual. Es posible que corresponda a la época de celo, septiembre-octubre, momento en que las astas se encuentran en su máximo desarrollo. No obstante, en el arte rupestre, e independientemente de su cronología, la figura del ciervo se observa en general con su cornamenta en su máximo desarrollo. Este es, de hecho, el único motivo figurativo de la Pedra da Póvoa.

La cara $\mathrm{D}$, situada a la derecha de la anterior y en la cara opuesta a la B, se encuentra severamente dañada en el lado derecho y en la parte superior, por fracturas del soporte que truncan una figura geométrica de la cual apenas quedan cinco arcos concéntricos (Fig. 2). Este motivo, grabado en el centro del panel, podría, eventualmente, tratarse de una combinación de círculos concéntricos o una espiral dextrógira, aunque esta última hipótesis sea la más probable visto que el surco más interior se cierra antes de alcanzar el límite de la fractura longitudinal y el exterior está abierto.

En suma, todas las caras del bloque granítico fueron previamente alisadas, con la excepción de

(2) Es evidente que el efecto visual de diferentes imágenes en el esquisto y el granito es el resultado de las características específicas de los dos tipos de medios de información geológica, que determina la gama de opciones para las técnicas de grabación. Sin embargo, parece posible establecer algunos paralelismos entre las imágenes de la Edad de Hierro incisas en esquisto y picoteadas en granito en relación, por ejemplo, a la morfología de las figuras zoomorfas. la parte más baja, que se presume que pudo haber servido de base y que estuviese enterrada. Los surcos de las figuras existentes en todas las caras muestran, genéricamente, una semejanza formal y técnica, con surcos bien conservados abiertos por piqueteado, cuya anchura raramente supera 1 $\mathrm{cm}$ y cuya profundidad oscila entre 0,3 y $0,5 \mathrm{~cm}$ Teniendo en cuenta lo dicho, se plantea como más que probable que toda la pieza hubiese sido concebida y ejecutada en un único momento.

\section{DISCUSIÓN Y PROBLEMÁTICA}

La Pedra da Póvoa presenta claros paralelismos con las denominadas "piedras onfálicas" o "pilares con decoración cuatripartita" (González Ruibal 2006-07: 548-550), cuya cronología más probable, según el citado autor, apunta a la fase final de la Edad del Hierro (Figs. 1 y 4). Muy posiblemente se tratarían de productos coetáneos a la escultura galaica que, según el mismo autor, se habría desarrollado en los siglos inmediatamente anteriores al cambio de era (González Ruibal 2004). Calo Lourido (1994) hace referencia a cuatro piedras del mismo tipo (Cortinhas, Alijó; Beiro, Ourense; Cendufe, Arcos de Valdevez; S. Miguel-o-Anjo, Famalicão), indicando que configuran piezas atípicas de función desconocida, aunque plantea la posibilidad de que se traten de posibles pilares de soporte. Por otro lado, y en relación a su posible finalidad, enfatizamos que los lugares en los que se encontraron estas cuatro piedras se sitúan, todos ellos, en las proximidades de importantes cursos de agua (los ríos Tua, Miño, Limia y Ave, respectivamente), así como la propia Pedra da Póvoa en relación al río Louredo.

Se ha propuesto que los santuarios de finales de la Edad del Hierro se localizasen en lugares fronterizos entre comunidades, propuesta corroborada por la significativa concentración en determinadas zonas de grabados rupestres y objetos de posible carácter sagrado como la Pedra da Póvoa, que se sitúan en las inmediaciones de ríos o en zonas más destacadas y elevadas, que, en todo caso, si no son fronteras políticas en la Prehistoria y en la Antigüedad, al menos son claras fronteras fisiográficas que constituyen discontinuidades territoriales (García y Santos 2008: 298-301).

El debate en torno a la datación de estas piezas no es ciertamente ajeno a la problemática so- 
bre los orígenes de la decoración arquitectónica "castreña". También en lo que respecta a su delimitación cronológica, las opiniones son algo discordantes, siendo Ferreira de Almeida (1986) defensor de su desarrollo entre la época Julio-Claudia y los Flavios. En cuanto J. Alarcão (1986) afirma que no podría ser anterior al siglo I d.C. Calo Lourido (1994) sitúa todo el arte galaico en el siglo I d.C., mientras que González Ruibal $(2004,2006-07)$ propone una cronología prerromana entre los siglos II y I a.C., asociada a la emergencia de los oppida y a los primeros contactos con el mundo romano.

Aunque con valor cronológico relativo, tenemos que mencionar la presencia de paralelismos distantes geográficamente a las "piedras onfálicas". Son las estelas de la Península Armoricana, como la de Kermaria (Finistère, Francia), que podrían datarse en el siglo IV a.C. y que presentan decoración semejante al tipo "SS" (Cunliffe 1997: 157-8). Otras con decoración tipo "SS" son las tres estelas o mojones de Melgven, Kervigérou; Pont L'Abbé, Keralio; Tréguennec, Finistère, también con formas troncocónicas y troncopiramidales y cuya cronología podría situarse en la transición entre la Primera y Segunda Edad del Hierro (Gomez y Milcent 2002). Estas tres últimas han sido localizadas en contextos funerarios. Otros ejemplos son las llamadas stone pillars como la de Pfalzeld (St Goar-Alemania), datada entre el siglo V y IV a.C. o la de Waldenbuch (Böblingen-Alemania), entre los siglos IV y III a.C., ambas con cuatro caras y con elementos decorativos semejantes a las mencionadas "SS" (Green 1996: 55; Cunliffe 1997: 61). Se podría mencionar asimismo la pieza de Turoe (Galway, Irlanda), que, aunque con forma cilíndrica, presenta, una vez más, la característica decoración combinando formas en S (O'Kelly 2001). En todos los casos, se tratan de esculturas o relieves con una cronología sensiblemente anterior a la propuesta para el Noroeste de Iberia.

Otro aspecto relevante es la presencia de tipologías próximas al Estilo Atlántico de arte rupestre. Destaca la figura del cérvido asociado a dibujos circulares o curvilíneos, tema recurrente en el Arte Atlántico, no sólo por los elementos decorativos, sino por la misma forma compositiva, con los diseños circulares en la parte superior y el cuadrúpedo en la inferior.

Remitimos a un trabajo futuro una discusión más profunda acerca de las implicaciones del ha- llazgo de esta pieza para una más precisa definición de las fronteras temporales de la tradición de Arte Atlántica y de la escultura galaica del Noroeste de Iberia. A nuestro juicio, la proximidad geográfica entre el área de distribución del Arte Atlántico más tardío que, entre otros, presenta tipologías que se aproximan a algunos motivos que decoran la Pedra da Póvoa (ciervos y motivos abstractos de tendencia circular), podría implicar la contemporaneidad entre la iconografía de la escultura en bajo relieve de la Edad del Hierro y los grabados rupestres de tradición Atlántica más tardíos. Recientes propuestas cronológicas, basadas en excavaciones arqueológicas y análisis iconográficos, apuntan a que el Estilo Atlántico siga en vigencia, por lo menos, hasta la primera mitad del I milenio a.C., aunque carecemos de información suficiente para estimar en qué momento se deja de producir (Santos 2005, 2008b). Se conocen diversos ejemplos de grabados pertenecientes a esta tradición reutilizados y sobrepuestos por construcciones de la Segunda Edad del Hierro, mientras que otros han sido parcialmente destruidos en ese mismo período pero, en los casos conocidos, se trata mayoritariamente de composiciones de círculos concéntricos que, por su morfología, podrían ser adscritos a la fase más antigua del Arte Atlántico, muy posiblemente anteriores a 2500 a.C. (3).

Queda abierta, por lo tanto, la posibilidad de que parte de la escultura galaica y parte de los petroglifos de Estilo Atlántico sean coetáneos. Esta posibilidad la mantiene el hecho de que buena parte del desarrollo de la escultura discurrió en paralelo a la formación de los oppida en los dos últimos siglos anteriores al cambio de era, pero no existen datos acerca de su origen cronológico. A este respecto debemos tener en cuenta las fechas atribuidas a los stone pillars europeos, que pueden remontarse al siglo V a.C. Por otra parte, las últimas propuestas cronológicas para el Arte Rupestre Atlántico no descartan prolongar la vida de estos petroglifos hasta el citado siglo. En todo

(3) Alves, L.B. 2003: The movement of signs. Post-glacial rock art in north-western Iberia. Tesis de Doctoramiento presentada en el Department of Archaeology de la University of Reading, Reino Unido. 2 vols. Policopiada.

Santos Estévez, M. (e.p.): "Una Propuesta Cronológica para el Arte Rupestre Atlántico". En F. Criado-Boado y A. Martínez Cortizas (eds.): Arte Rupestre, paleoambiente y paisaje. Miradas interdisciplinares sobre Campo Lameiro. Traballos de Arqueoloxía y Patrimonio. Trabajos de Arqueología del Paisaje. CSIC. Santiago de Compostela. 
caso, queda constatada la existencia de influencias iconográficas entre ambas expresiones artísticas, las cuales se materializan en la presencia, tanto en escultura como en grabados rupestres, de diseños comunes: cérvidos, círculos concéntricos, espirales, diseños en "SS", trísqueles y esvásticas. Para el caso concreto de La Pedra da Póvoa debemos sumar la circunstancia de la técnica empleada: el falso relieve, propio del Arte Atlántico y menos común en la escultura "castreña".

La cuestión estaría ahora en resolver si la escultura galaica y el Arte Atlántico son realmente coetáneos, o si la primera heredó motivos ya creados con anterioridad para los petroglifos.

\section{AGRADECIMIENTOS}

Se agradece la revisión y comentarios de Marco V. García Quintela y César Parcero Oubiña, así como a Anxo Rodríguez Paz la ayuda en la preparación de las imágenes. Se agradece también los sugerentes comentarios de los revisores anónimos.

\section{BIBLIOGRAFÍA}

Alarção, J. 1986: A Arte do Bronze Final e da Idade do Ferro, História da Arte em Portugal I. Ed. Alfa: 57-65.

Almeida, C.A.F. 1986: “Arte castreja. A su lição para os fenómenos de assimilação e resistência à romanidade". Arqueologia 13: 161-172.

Alves, L.B. 2008: "O sentido dos signos-reflexões e perspectivas para o estudo da arte rupestre do pós-glaciar no Norte de Portugal". En R. de Balbín Behrmann (ed.): Arte Prehistórico al aire libre en el sur de Europa, Junta de Castilla y León: 381-413.

Arizaga Castro, A.; Fábrega Álvarez, P.; Ayán Vila, X. y Rodríguez Paz, A. 2006: “Apropiación Simbólica de la Cultura Material Castrexa en la Paisaxe Cultural dos Chaos de Amoeiro". Cuadernos de Estudios Gallegos LIII, 119: 87-129.

Baptista, A.M. 1999: No tempo sem tempo. A arte dos caçadores paleolíticos do Vale do Côa. Parque Arqueológico do Vale do Côa. Vila Nova de Foz Côa.

Calo Lourido, F. 1994: A plástica da cultura castrexa galego-portuguesa. Fundación Pedro Barrié de la Maza. A Coruña.

Carvalho, M.J. 1981: O santuário rupestre de Lamelas, Ribeira de Pena. Câmara Municipal de Ribeira de Pena. Ribeira de Pena.
Comendador Rey, B. 1999: Los inicios de la Metalurgia en el Noroeste de la Península Ibérica. Museo Aqueolóxico e Histórico. Monografías 11. A Coruña.

Cunliffe, B. 1997: The Ancient Celts. Oxford University Press. Oxford.

Dinis, A. 2001: O povoado da Idade do Ferro do Castroeiro (Mondim de Basto, Norte de Portugal). Cadernos de Arqueologia-Monografias 13, Unidade de Arqueologia da Universidade do Minho. Braga.

Freitas, A.M. 2001: Carta Arqueológica do Concelho de Valpaços. Câmara Municipal de Valpaços. Valpaços.

García Quintela, M.V. y Santos Estévez, M. 2008: Santuarios de la Galicia Céltica. Arqueología del Paisaje y Religiones Comparadas en la Edad del Hierro. Abada Editores. Madrid.

Gomez de Soto, J. y Pierre-Yves, M. 2002: "La sculpture de l'âge du Fer en France centrale et occidentale". Documents d'archéologie méridionale 25: 261-267.

González Ruibal, A. 2004: "Artistic expression and material culture in Celtic Gallaecia". e-Keltoi Journal of Interdisciplinary Celtic Studies 6. The Celts in the Iberian Peninsula: 113-166.

González Ruibal, A. 2006-07: "Galaicos: poder y comunidad en el Noroeste de la Península Ibérica (1200 a.C.-50 d.C.)". Brigantium 19, Boletín del Museu Arqueolóxico y Histórico de la Coruña.

Green, M. 1996: Celtic Art. The Orion Publishing Group. London.

O’Kelly, M.J. 2001: Early Ireland. An introduction to Irish prehistory. Cambridge University Press. Cambridge

Menezes, M. 1929: "Notícias arqueológicas del concelho de Ribeira de Pena". O Arqueólogo Português 1." série 27: 29-48.

Santos Estévez, M. 2005: "Sobre la cronología del arte rupestre atlántico en Galicia". Arqueoweb 7(2). 2005. (http://www.ucm.es/info/arqueoweb/numero7 2/conjunto7_2.htm)

Santos Estévez, M. 2008a: Petroglifos y paisaje social en la prehistoria reciente del NW de la Península Ibérica. Traballos de Arqueoloxía y Patrimonio Tapa 38. IEGPS-CSIC. Santiago de Compostela.

Santos Estévez, M. 2008b: "A new proposal for the chronology of Atlantic rock art in Galicia (NW Iberian Peninsula)". En G. Nash y G. Children (eds.): Archaeology of Semiotics and the Social Order of Things. British Archaeological Reports International Series 1833, Archaeopress. Oxford: 141-152.

Schattner, T. 2004: "Novas aproximações às estatuas de guerreiros lusitano-galaicos". O Arqueólogo Português série IV: 22 9-66.

Vasconcelos, J.L. 1917: “Coisas velhas”. O Arqueólogo Português 1. a série 22: 107-169. 